\title{
The General Principles of the Transportation Simulation Model Development and Validation
}

\author{
NADEZDA ZENINA \\ YURI MERKURYEV \\ ANDREJS ROMANOVS \\ Department of Modelling and Simulation \\ Riga Technical University \\ 1 Kalku Street, Riga \\ LATVIA \\ nadezda.zenina@rtu.lv
}

\begin{abstract}
Transportation simulation model development allows simulating traveller's decisions, evaluating various transportation management strategies and complex solutions. The aim of the paper is to set the general principles of the transportation simulation model development and validation. The paper contains the overview of the transportation simulation models types with the examples from the conducted projects for the Riga city. The basic steps of the simulation model development procedure: initial data preparation and analysis, transportation model development and simulation, scenarios planning and evaluation, and simulation models outcomes evaluation are considered. Simulation model verification, validation and calibration definitions are given. The basic checks for the transportation macroscopic and microscopic simulation model validation are listed. A summary of the transportation simulation model validation and calibration methods and parameters is given.
\end{abstract}

Key-Words: - Simulation, transportation, development, validation, verification, microscopic, macroscopic

Received: September 10, 2019. Revised: March 8, 2020. Accepted: March 19, 2020. Published: April 3, 2020.

\section{Introduction}

Nowadays, simulation has become one of the most common research methods in the transportation planning and analysis to provide the sustainable transportation systems, increase the accessibility of the transportation infrastructure, improve the availability of means of transport, increase the mobility for the non-motorized transportation system participants, reduce congestions and driving time etc. Transportation simulation is based on the mathematical models that imitate drivers' decisions and evaluate complex transportation management solutions and tasks [2]. Transportation simulation models allow:

- Simulating systems, that very difficult or impossible to evaluate analytically.

- Checking new solution before implementation in the real environment. It is safer, cheaper and faster solution.

- Determining "bottlenecks" in the transportation network.

- It helps to understand how a complex transportation system works.

In order to measure the performance of transportation system, a good understanding of the traffic flow dynamic at microscopic and macroscopic level, drivers and traveler behaviors and trends in road use, the impact of congestions on the street network is essential. The paper contains the description of the main transportation simulation models types - macroscopic, mesoscopic, microscopic and hybrid. Development of the transportation simulation model is considered step by step, following the simulation model development procedure. The figures in the paper represent the examples of the various transportation models for projects conducted in the Riga city.

Simulation model validation usually done during simulation model development in order to make sure that in the particular stage of the model development the simulation results qualify the initial defined requirements [3, 4]. Simulation model verification, validation and calibration definitions are listed to represent that there is not one unified definition of these terms. And to highlight the importance of the fact that developers should agree on the checking terms definition before the transportation simulation model development process. Checking process have common and differ checks for the macroscopic and microscopic simulation models, because of the different model scale and level of details. A summarization of the mains checks for transportation macroscopic and microscopic simulation model validation is 
presented. The examples of validation are presented for the macroscopic simulation model with GEH statistics and the microscopic simulation model with root mean square error.

\section{Transportation simulation models}

Simulation models belong to macroscopic (Fig.1) microscopic (Fig.2), mesoscopic (Fig.3) and hybrid models. Transportation macroscopic simulation models simulate the whole vehicles' behavior, focusing on global factors simulation (e.g., land use, socioeconomic, demographic etc.). To describe the transportation intensities the following parameters are used: flow, density and average speed, etc. Macroscopic transportation simulation models are classified into static and dynamic.

Static macroscopic simulation model is not timedepending and does not include the congestion impact on the transportation assignment. In turn, dynamic macroscopic simulation model takes into account congestion impact on the transportation intensities distribution (for example, based on the fundamental diagram).

There are several commercial transportation simulation tools for macroscopic model development, e.g. Aimsun, Vissum, Emme, Cube etc.

The Example of the macroscopic static simulation model assignment results of the central part of the Riga city is shown Fig 1. Transportation assignment was made with commercial transportation integrated simulation tool Aimsun (Advanced Interactive Microscopic for Urban and Non-urban networks). Aimsun tool provide discrete, continuous and combined simulation; the macroscopic functionality include the four-step travel demand modeling [9, 30].

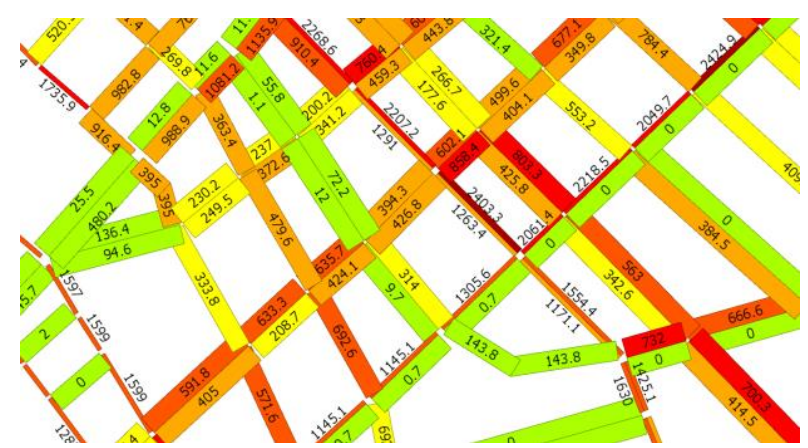

Fig.1. The example of the macroscopic simulation model assignment results of the central part of the Riga city [36].

Transport microscopic simulation model imitates the behavior of a single vehicle during the stated period of time, while the definite vehicles behavior patterns (e.g., car following) are assigned to the driver that crosses the road network. There are several transportation simulation tools for the microscopic model development, e.g. Syncro, Aimsun, Transyt, Vissim, Paramix, Corsim etc. Aimsun tool provide a transportation network simulation in detail, divides vehicles and drivers into a categories, uses different road network geometries, allows simulating road traffic accidents and conflicting turnings for the microscopic simulation models.

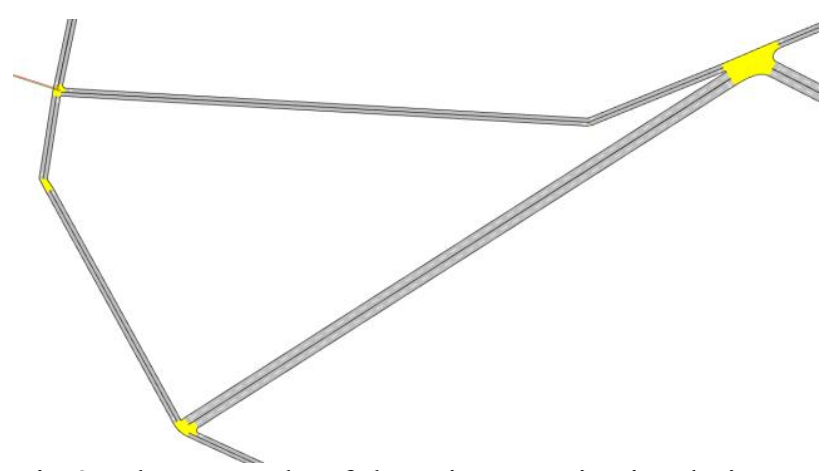

Fig.2. The example of the microscopic simulation model [38].

Transportation mesoscopic simulation models combine the characteristics of the microscopic and macroscopic simulation models. Mesoscopic simulation models describe the simplified view of the traffic flow dynamic; individual vehicles are simulated, but to determine vehicles behaviour, macroscopic simulation model relationships are used (Fig.3).

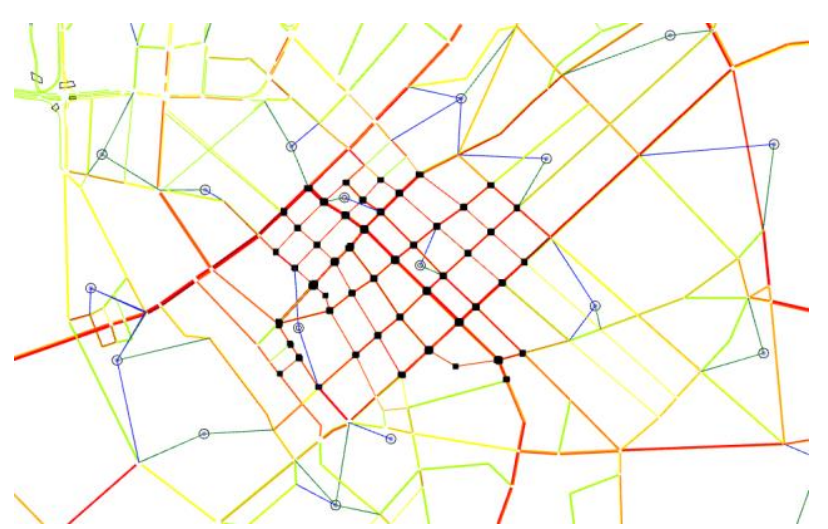

Fig.3. The example of the mesoscopic simulation model.

Mesoscopic transportation simulation models can dramatically differ from one another based on the selected transportation simulation methodology. Some mesoscopic simulation models are closer to 
macroscopic simulation models, others to microscopic model.

Transportation hybrid simulation models are the combination of the macroscopic and microscopic simulation model, and one or another simulation model condition can be used depending on the transportation system objectives and tasks. For example, the microscopic simulation model features can be used to simulate the vehicles behaviour at the single intersections, and macroscopic features can be used to simulate the vehicle's behaviour at street sections between the intersections [8].

\section{Development of the transport simulation model based on simulation procedure}

The development of the transportation simulation model generally is done based on the basic steps of the simulation procedure. The microscopic simulation model is developed based on the combined, discrete and continuous simulation model. The simulation procedure basic steps include the problem formulation and tasks definition, conceptual model development, input data preparation, simulation model drawing and programming, verification, validation, planning and design of experiments, and results evaluation and observation (Fig.4).

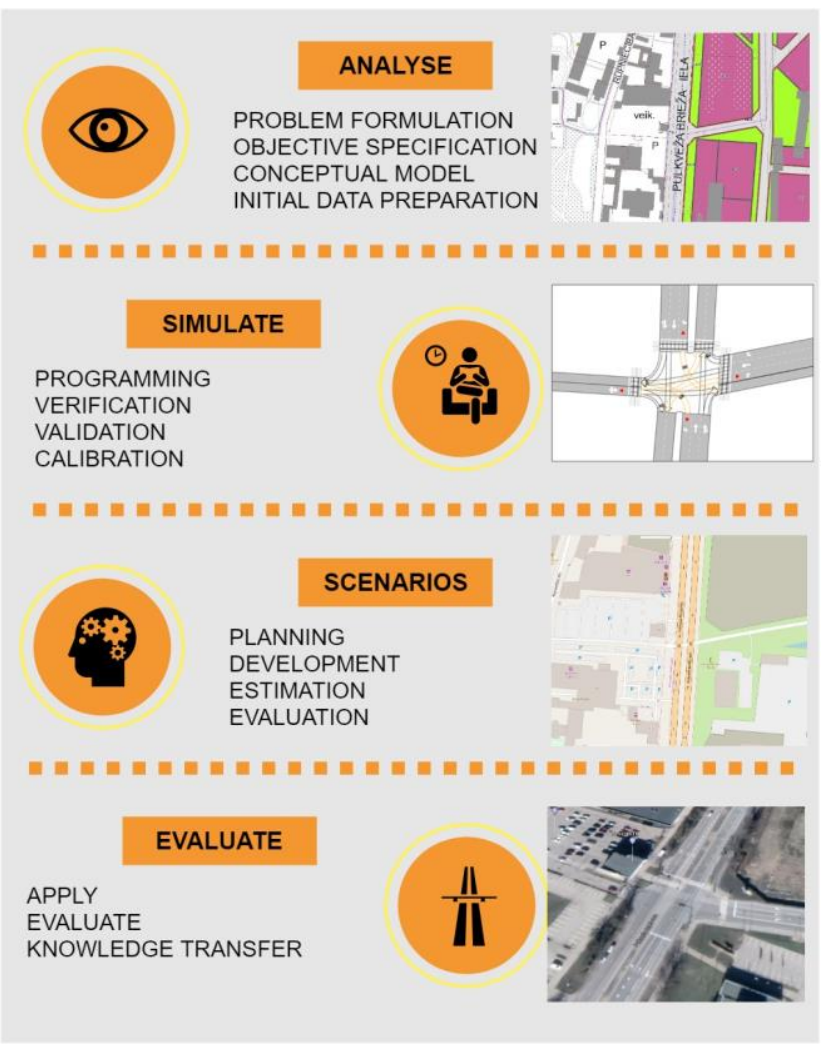

Fig.4. The basic steps of the simulation procedure for the transportation model development.

\subsection{Initial data preparation and analysis}

Initial data preparation and analysis is the first step of the simulation procedure for the transportation model development. This step includes initial data collection and preprocessing (geometry data, intensity data etc.), identification of the possible solutions and restrictions for the transportation system, such as analysis time, size of the research zone, number of the analyzed intersections etc.

In this step assessment methods are selected, analysis methods are determined, and decision is made about the simulation model development. The type of the developed simulation model is determined - macroscopic, microscopic or mesoscopic. In most cases the type of the simulation model will depend on the tasks. For example, if it necessary to analyse the possible locations of the Park and Ride parking around and inside the Riga city, evaluate the impact of the parking on the transportation infrastructure, estimate the changes of the transportation intensities over a long period of time, take into account Riga city development plans with new streets, bridges and others large-scale infrastructure objects, the macroscopic simulation model can be the acceptable choice. The example of the macroscopic simulation model transportation assignment results for Park\&Ride project is shown in Fig.5. Assignment results show the streets capacity in the central part of the Riga city in 2025 year with Park\&Ride parking.

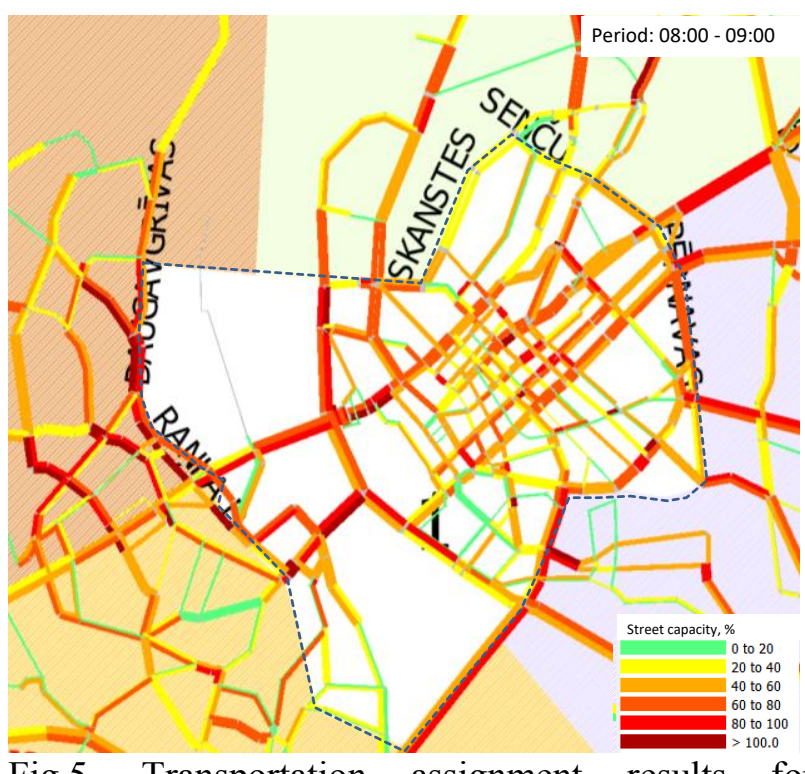

Fig.5. Transportation assignment results for Park\&Ride project, 2025 year [36]. 
In case if necessary to determine the number of generated trips by the some small object, to distribute the new traffic and assign it to the transportation network; to evaluate and recommend traffic organization changes (lanes, signal timing etc.) at accesses, intersections and sections in the definite research area, then the acceptable choice is microscopic simulation model. The examples of the microscopic simulation model animation for the transport impact analysis project in the Riga city is shown in Fig.6. The aim of the project was to make changes in the research area to reduce the new object impact on the transportation network and improve the routes capacity.

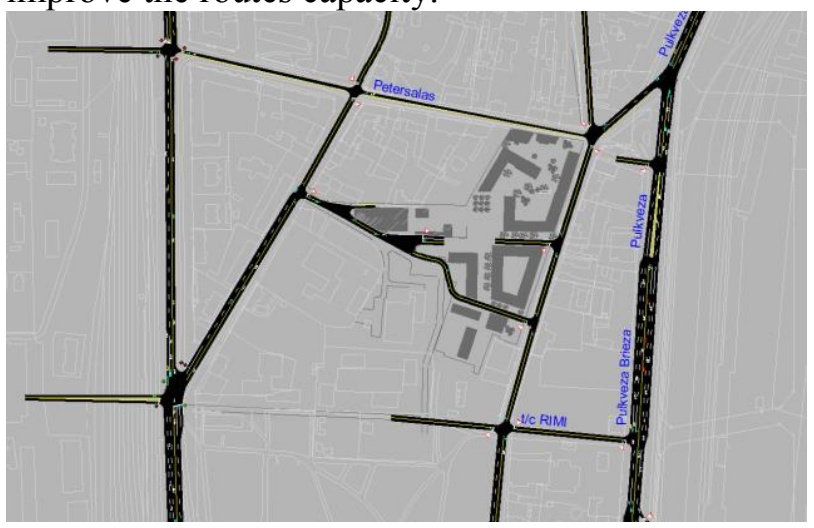

Fig.6. The example of the microscopic simulation model animation for the transport impact analysis project [37].

If the simulation would be part of an analysis, then conceptual model is developed. The conceptual model should be simple, clear, and understandable and follows SMART (Specific, Measurable, Attainable, Realistic, Timely) principle [32].

\subsection{Transportation model development and simulation}

Simulation model development includes the transportation network drawing, programming, signal planning, transportation demand data (cars, trucks pedestrian, cyclists' intensities) input into the simulation model, model verification, validation and calibration [14].

Transportation simulation drawing including lanes, reserved lanes, turnings, nodes etc. depends on the selected simulation tool. Each transportation simulation tool has its own characteristics. It is important to draw the intersections and geometry of the street network to provide that the developed transportation system is as close as possible to the observed ones.

The example of the working mode for microscopic simulation model for the Synchro tool is shown in
Fig.7. Blue color represents the transport lanes and arrows show the intensities at the intersections.

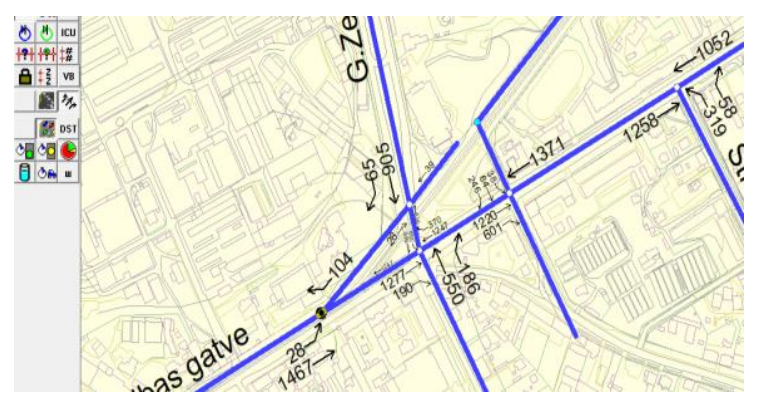

Fig.7. Working mode for geometry data input in the Synchro transportation simulation tool [39].

Another example, the working mode for the intersection geometry drawing in Aimsun tool is shown in Fig.8.

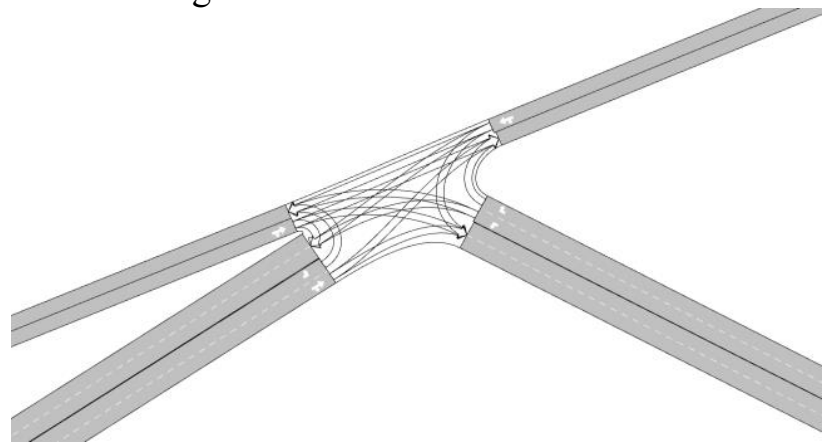

Fig.8. Working mode for geometry data input in the Aimsun transportation simulation tool [38].

In most cases, the simulation tool selection is limited to the tool that already is available to the developer. The tool selection also can depend on the tasks that should be done. For example, if task is to do the intersection signal timing optimization, the acceptable choice is the Synchro or Transyt transportation simulation tool. If the task is to do transportation intensities assignment for the whole city, the modeling some small areas, then acceptable choice could be Aimsun or Vissim/Vissum transportation simulation tool.

After the geometry of the transportation network and other input data are added, programming is performed, the next step is to do simulation model checking (chapter 4 for details).

\subsection{Scenarios planning and evaluation}

The next step of the simulation procedure is to design and plan scenarios, and estimate and evaluates the transportation simulation model outcomes.

In this step is highly recommended to pay attention to the number of the scenarios. Too many scenarios can lead to the situation, when only developers will 
understand the difference between scenarios, and practically impossible will be clear define the benefits of the each developed scenario to the customer and select acceptable one.

The example of the microscopic simulation model animation with too many scenarios is shown in Fig.9. It is the central part of the Liepaya city in the Latvia. The aim of the project was to analyse different traffic organization changes in the whole research area [38]. The changes included: change some streets directions, restrict vehicles movements at some streets, and change some intersections traffic organization (e.g., provide left turn or right turn pockets, prohibited some left turns), offset tram lanes, develop signalizing at some intersections, change some intersection from unsignalized to signalized or maybe to roundabout, add public transport lanes etc.

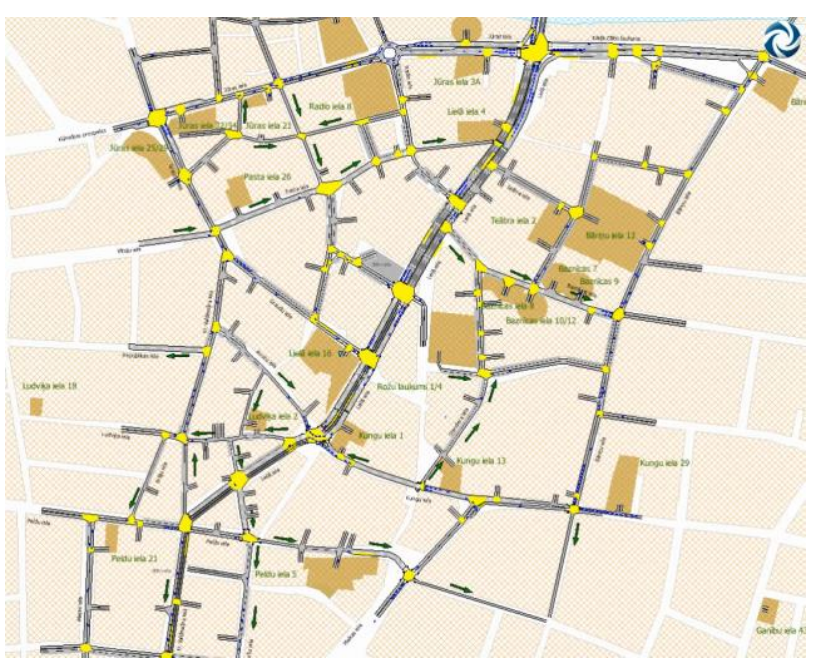

Fig.9. The example of the microscopic transportation simulation model animation in Aimsun tool [38].

And all these changes were simulated and checked firstly one by one and then all together. But in time the number of scenarios increases, because all the time changes in the requirements: what if left changes from $A$ to $D$, but $E$ and $D$ changes removed from scenario. And now remove A and B changes and add $\mathrm{E}$ change. In the result more than sixty scenarios were developed, in which developer was able to somehow navigate, but mostly it was impossible to describe the benefits and disadvantages to others. And it returns to the simulation procedure basic steps - plan the number of the scenarios and to the first step of procedure define the restriction.

\subsection{Simulation models results evaluation}

The estimation step of the simulation procedure includes results evaluation in the real environment, e.g. when intersection had been reconstructed according to the proposed improvements, does the specified number of lanes for each road section correspond to the observed data, any unexpected events was occurred etc. All these finding should be used to evaluate results of simulation and transfer knowledge.

\section{Simulation model verification, validation and calibration definitions}

The purpose of the transportation simulation model verification, validation and calibration is to provide that simulation outputs do not exceed the expected results and an abnormal tendencies do not occurred (e.g., the vehicles cross the intersection at red light signal, pedestrians cross the road with vehicles in one time, vehicles run through one another etc.). But, if this happens, the reasons for such behaviour might be input data errors, expectations errors or animation errors [33]. In such cases, input data, parameters, geometry of the street network, and observed driver behaviour data on the road should be rechecked. Sometimes simulated outcomes do not correspond to the observed ones, and error exists in the observations, not in the model. Sometimes errors are associated with the representation of the objects, improperly drawn cars trajectories, incorrect road sign placement, cars spin around themselves (Fig.10), human errors etc. As the result simulation model does not match the observed one and cannot be used for further analysis. In order to minimize such situations, the transportation simulation model needs to be thoroughly checked.

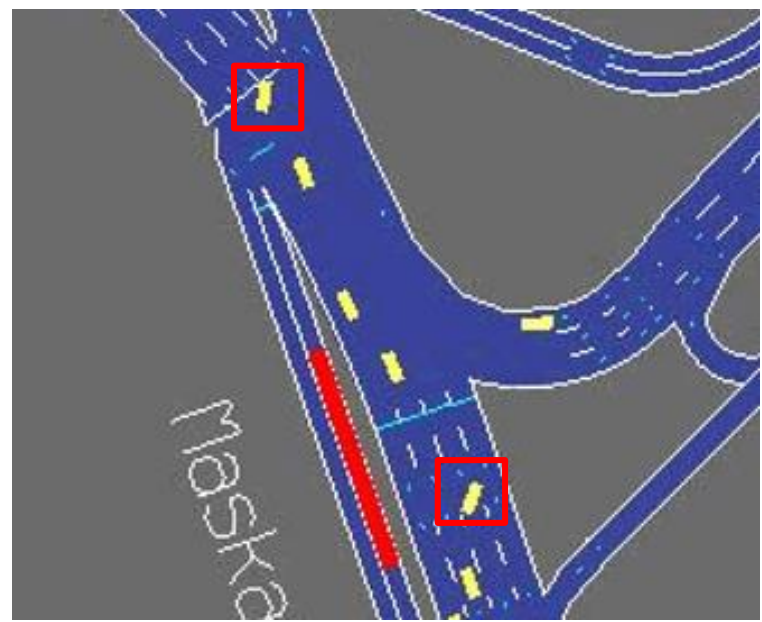

Fig.10. Animation error example: cars spin around themselves. 
There is no single unified validation, verification and calibration definition, see Table 1.

Table 1. Simulation model verification, validation and calibration definitions

\begin{tabular}{|c|c|c|c|}
\hline Validation & Verification & Calibration & Source \\
\hline $\begin{array}{l}\text { The process of determining whether the logic of the } \\
\text { simulation model is correctly represented in a computer } \\
\text { program. Validation states that simulation results } \\
\text { correspond to the model logic. Validation does not } \\
\text { check simulation model consistently with proposed } \\
\text { model logic or theory on which the logic was based. }\end{array}$ & $\begin{array}{l}\text { The process that determines how the } \\
\text { developed transportation simulation model } \\
\text { represents the actual transportation situation. }\end{array}$ & $\begin{array}{l}\text { The process in which the user } \\
\text { determines set of the input } \\
\text { parameters to represent local } \\
\text { transportation regulations. }\end{array}$ & {$[6]$} \\
\hline $\begin{array}{l}\text { The process of checking whether simulation model is } \\
\text { representative, based on calibration data and the whole } \\
\text { transportation system analysis. In practice, model } \\
\text { validation is calibrated, which means the model output } \\
\text { comparison with input data that were not included in } \\
\text { the calibration process. }\end{array}$ & $\begin{array}{l}\text { The reviewing process of the simulation } \\
\text { model development to make sure that model } \\
\text { is working as expected. }\end{array}$ & $\begin{array}{l}\text { The process of the parameters } \\
\text { adjustment to model the real } \\
\text { transportation system. }\end{array}$ & [9] \\
\hline $\begin{array}{l}\text { The process in which the user checks the total forecast } \\
\text { capabilities of the transportation network in terms of } \\
\text { the traffic flows, travel times, average speeds and } \\
\text { average delays. }\end{array}$ & $\begin{array}{l}\text { The process to avoid the problems in the } \\
\text { calibration process. Simulation model } \\
\text { verification is not considered as a separate } \\
\text { step in the validation process. }\end{array}$ & $\begin{array}{l}\text { The process in which user selects } \\
\text { parameters of the simulation model } \\
\text { that realistically reflect the } \\
\text { researched transportation system. }\end{array}$ & {$[5]$} \\
\hline $\begin{array}{l}\text { The testing process that determines the simulation } \\
\text { model viability and usefulness in comparison with the } \\
\text { transportation model under the study. It also requires } \\
\text { model calibration, model parameters adjustment until } \\
\text { the model output will be close to expected. }\end{array}$ & $\begin{array}{l}\text { Verification is considered as part of } \\
\text { validation. }\end{array}$ & $\begin{array}{l}\text { The process of the adjusting the } \\
\text { parameters values and others user- } \\
\text { controlled variables to match the } \\
\text { modelled transportation flow } \\
\text { intensities with observed. }\end{array}$ & {$[3]$} \\
\hline
\end{tabular}

the model output will be close to expected.

In simulation model validation is necessary to check

Validation and calibration steps are used in any transportation simulation model checking process. Simulation model verification is used by the individual authors and in the validation guidelines as the third additional check for the validation and calibration. In other cases, validation includes the validation and calibration steps and simulation model verification occurs during the validation process. Sometimes verification is used as a synonym for validation, and in some cases is called evaluation and testing [3].

It is significant to ensure that simulation model development team agrees on definitions terms and meanings before the simulation model checking process.

The author the simulation model validation defines as process in which it is checked, how well transportation simulation model fits the observed transportation system by comparing simulated and observed transportation system logic and structure, by adjusted calibration parameters in the way that they are consistent with observed transportation system, and by checking that simulation model effectiveness measures adequately describe the observed transportation situation. Simulation model validation includes validation and calibration steps where simulation model verification occurs during the validation process.

\section{Simulation model validation}

that input data and specific parameters are correctly added into transportation simulation model, and no errors in the numerical parameters or basic settings. Validation process have common and differ checks for the macroscopic and microscopic simulation models, because of the different models scale and level of details.

\subsection{Transportation macroscopic simulation model validation}

In most cases macroscopic transportation simulation models are developed basing on the four-step transport travel demand model (trip generation, trip distribution, and transportation mode choice and trip assignment). The first step of macroscopic simulation model validation is to ensure that the each step of the four-step transport travel demand model is properly validated. [35]. Next step is to check simulated model traffic data (intensities on the key intersections, flow structure etc.) and infrastructure data (number of lanes, restricted turns, reserved lanes for public transport, timing, calculated section capacity etc.). The following checks should be carried out:

- Load at connectors. Simulation model can have multiple connections points (connectors) that are connected to transportation network. Check that capacity distribution at these connectors match the observed ones. Check that connectors are not connected to the intersections, but are connected to streets with the low category. 
- Street and route categorization. Check that street and route categories correspond to the normative acts and documents accepted for the research area.

- Section capacity. Check the entered section capacity, each street and route category is assigned to own volume delay function.

- Transport intensity. Check that transportation intensities on the individuals sections and turns correspond to observe ones.

To determine the correctness of data checks recommended conducting the sensitivity tests. Transportation assignment should be done by decreasing free flow speed by $10 \%$ then by $20 \%$; decreasing public transport usage by some percent; increasing traffic flow intensity by some percent etc. All these actions help to determine the atypical and odd patterns in the transportation network and improve the simulation model correctness.

Measured intensities values at intersections and travel time between main origin and destination points can be used to do the macroscopic transportation simulation models calibration. Calibration of the simulation model transportation intensities made based on the GEH statistics (1) by comparing observed and simulated transportation intensities.

$$
G E H=\sqrt{\frac{2(s-o)^{2}}{s+o}}
$$

where $\mathrm{s}-$ observed transportation intensity.

$\mathrm{o}-$ simulated transportation intensity.

Validation with GEH statistics is considered acceptable, if values of the GEH are between 0 and 5 (good score). If values of the GEH are greater than 10 , validation is unacceptable; the observed and simulated transportation intensities differ significantly. The values of the GEH in the range of 5 to 10 require an additional in-depth analysis [34]. According to the [34] at least $85 \%$ of the road sections must be GEH value less than 5 score and at least $90 \%$ of the road sections must be GEH value in the range of 5 to 10 score.

The example of the GEH statistics results for the macroscopic simulation model for the Riga city (EMME model, morning scenario, maximum hour) is shown in the Table 2. The view of macroscopic simulation model for the Riga city is shown in the Fig. 14 (colours represent the transportation intensities; dark red colour - high intensities).

Table 2. Example of the GEH statistics for the macroscopic simulation model

\begin{tabular}{|c|c|c|}
\hline $\mathrm{GEH}<5$ & $5<\mathrm{GEH}<10$ & $\mathrm{GEH}>10$ \\
\hline $26 \%$ & $56 \%$ & $18 \%$ \\
\hline
\end{tabular}

The GEH value is between 5 and 10 score for the several road sections, transportation simulation model validation is unacceptable and necessary to carry out additional simulation model validation and check the input data, load at connectors, street categories, added street capacity, allowed speeds and transport intensity. The error cause should be finding in the parameters of the transportation simulation model or in input data.

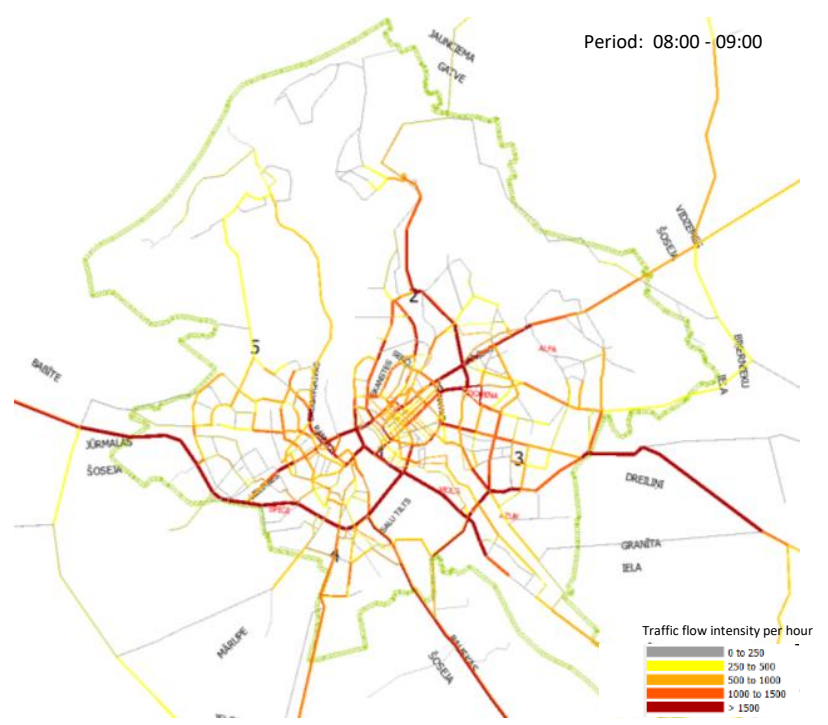

Fig.14. The example of the EMME macroscopic simulation model for the Riga city [36].

\subsection{Transportation microscopic simulation model validation}

The following checks should be done for the transportation microscopic simulation model:

- Input data. Check that specified parameters e.g., intensities, number of lanes, signs, permitted speed, traffic lights, intensities match the observed.

- Basic settings. Check the basic parameters of the simulation tool. Number and type of parameters will depend on the selected simulation tools.

- Geometry data. Check that number of lanes, lane widths, allowed directions and speeds, turns corresponds to the observed.

- Driver behaviour parameters. Check the lane changing and queue discharge parameters, overtaking and car-following models etc.

- Transportation flow intensities (cars, trucks, pedestrian, cyclists, public transport, etc.). Check intensities for typing errors, traffic 
lights and cycle length input errors, vehicles interfere with each other's in the transportation network.

- Road user cooperation. Check public transport priority on transit lanes, cooperation between cars and pedestrian at intersections.

The simple simulation model for the single intersection in the Riga city, in the Pulkveza Brieza street area was developed to demonstrate the initial steps for the transportation microscopic simulation model validation (Fig. 15).

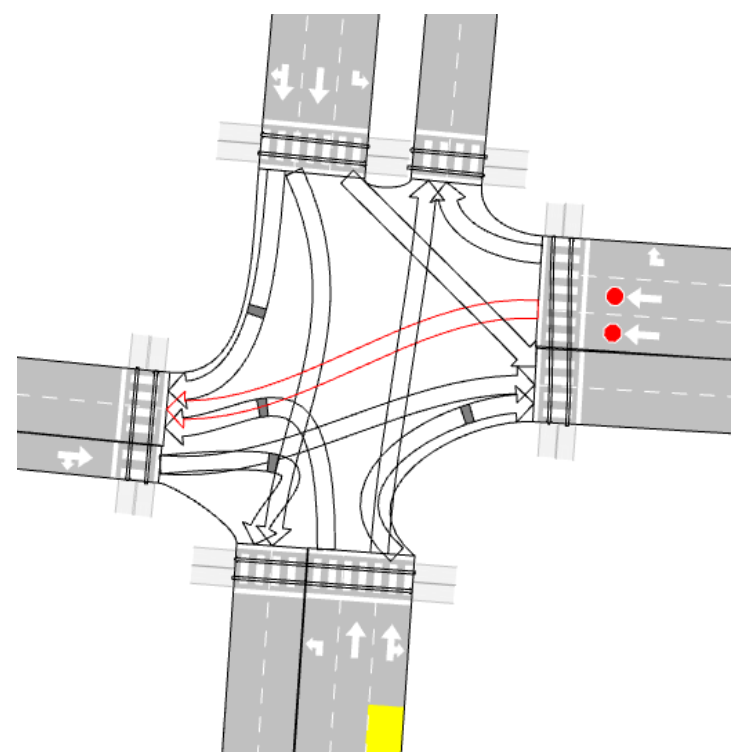

Fig.15. The initial developed simulation model.

The input data for the transportation simulation model included intersection geometry (number of lanes, allowed turns, pedestrian crossings, stop lines, signs, public transport stops), signal timing data (signal groups, signal phases, control type, cycle length) and transportation intensity data (cars, trucks, pedestrians, cyclists; schedule and frequency data were added for public transport).

The initial step of the simulation model validation is to check correctness of the entered data and parameters. For the developed simulation model (Fig. 15) the checking was done by answering the following questions:

- Intersection geometry. Whether the specified number of lanes, turns, stop lines and signs corresponded to the observed?

- Signal timing. Whether the specified signal controls corresponded to the observed?

- Transportation intensity. Whether the specified intensities for the cars, trucks, pedestrians corresponded to the observed?

If there were some "No" answers, then transportation simulation model was changed according to observed situation. The result of the initial simulation model validation for the developed intersection is shown in Fig. 16.

There are several methods to determine the correctness of data checks. Some of them include the simulation model run with the moderate load or the maximum load, and review of how the system behaves (e.g., vehicles behave atypically, major congestions or queues do not detect) and how many vehicles can drive through the system under such condition.

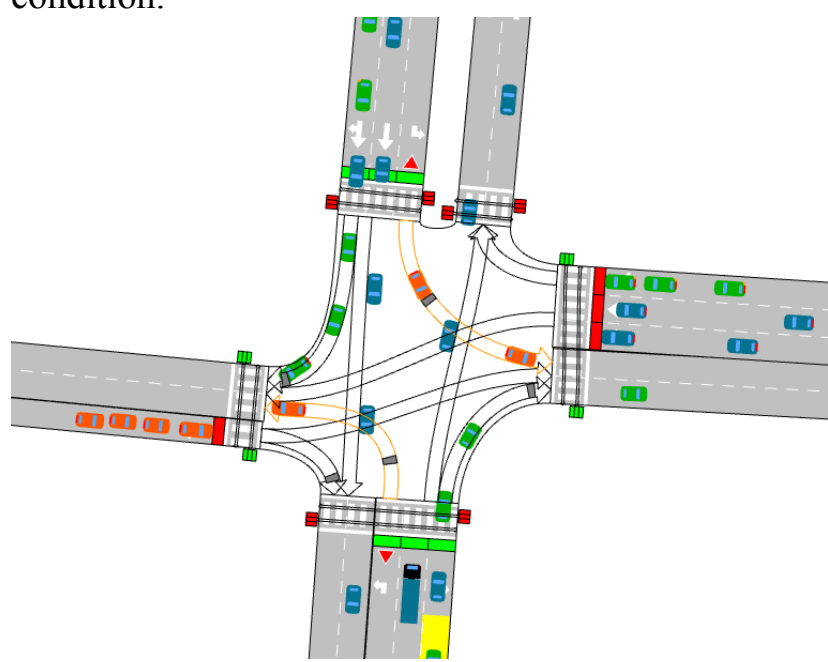

Fig.16. The results of the initial simulation model validation for the single intersection.

Other methods include the observation of the individual travel routes with the highest transportation intensity, of the potential conflicting situation that may involve multiple road users [33]. All these actions allow reviewing transportation simulation model for input errors. As the result of these actions, transportation simulation model is ready for further model validation and calibration.

\subsection{Validation methods}

Validation methods divide into quality methods and quantitative methods. Quality validation methods include the graphical results comparison (e.g., animation, graphs and histograms) with others simulation model outputs, and model behaviour research.

The example of the quality validation method usage (average approach delay for the evening maximum hour) for developed single intersection is shown in the Fig. 17.

Quantitative validation methods include the model outputs analysis with statistical methods, e.g., percent error, root mean square error (2), mean percentage error, GEH statistics or Theil's uncertainly coefficient $[3,10,11,12,22]$. 


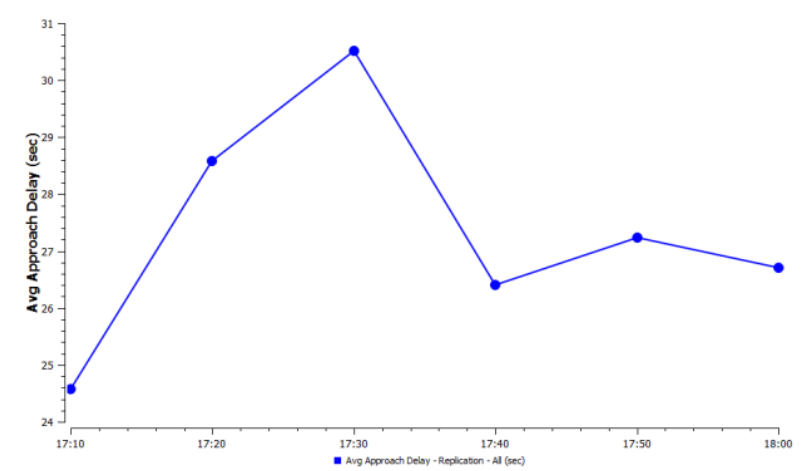

Fig.17. The average approach delay for the developed single intersection.

$$
\operatorname{RMSE}_{i}=\sqrt{\frac{1}{n} \sum_{j=1}^{n}\left(w_{i j}-v_{i j}\right)^{2}},
$$

$\begin{array}{llll}\text { where } & n & - & \text { number of records; } \\ & w_{i j} & - & \text { modelled transport flow } \\ & & \text { intensity; } \\ & v_{i j} & - & \text { observed transport flow. }\end{array}$

The example of the root mean square error calculation for developed single intersection in the Riga city (Fig. 15, Fig. 16) is shown in Table 3. Three groups with varied changes in the traffic organization were developed during the initial validation stage of the transportation simulation model. The first group was without any change in the traffic organization. The second group provided changes for signs and connections trajectories. And the third group provided changes for the stop lines. Root mean square error was calculated for the four access road sections for the each group to observe any changes in the road sections and impact on the analysed transportation system.

Table 3. Results of the RMSE calculation

\begin{tabular}{|l|c|c|c|c|}
\hline \multirow{2}{*}{$\begin{array}{l}\text { Changes in the } \\
\text { transportation } \\
\text { system }\end{array}$} & $\begin{array}{c}\text { RSME values } \\
\text { sectio } \\
\mathrm{n}\end{array}$ & $\begin{array}{c}2 . \\
\text { sectio } \\
\mathrm{n}\end{array}$ & $\begin{array}{c}3 . \\
\text { sectio } \\
\mathrm{n}\end{array}$ & $\begin{array}{c}4 . \\
\text { sectio } \\
\mathrm{n}\end{array}$ \\
\hline $\begin{array}{l}\text { No changes (Fig. } \\
15)\end{array}$ & 160 & 611 & 288 & 42 \\
\hline $\begin{array}{l}\text { Signs and trajectory } \\
\text { changes }\end{array}$ & 203 & 356 & 280 & 30 \\
\hline $\begin{array}{l}\text { Stop lines changes } \\
\text { with signs and } \\
\text { trajectory (Fig. 16) }\end{array}$ & 203 & 356 & 280 & 36 \\
\hline
\end{tabular}

RMSE calculation results showed that the relevant road signs and connection trajectories have the most significant impact on the transportation intensities.
By changing the trajectories, removing the stop lines and pointing out the road signs, the transportation intensities rate doubled for all lanes. And by changing at least one parameter in the simulation model can improve transportation flow and reduce congestion. It is recommended to analyse the each road section individually and change the parameters based on its characteristics.

\subsection{Calibration parameters}

The selection of the validation and calibration parameters and transportation system performance indicators depend on the task complexity, initial data quantity and quality. Several parameters are used to evaluate the performance of transportation system model and to obtain the acceptable and reliable results. Standard model parameters are iteratively adjusted until a satisfactory level between modelled and observed data is achieved. It is tedious and time-consuming process when it's done manually, even if some engineering techniques are used to reduce the number of attempts. Automated simulation model calibration is based on the systematic approach. This approach views the model calibration as an optimization problem that looks for the parameters value combinations that best describe the target function, e.g., performs microscopic simulation model calibration with the genetic algorithms to calibrate the global and local model capacity parameters. The function objective is formulated as a black box model and solution is searched using heuristics. The computation complexity is exponential. Optimization procedures require a large number of attempts, which in turns are time-consuming process and depends on the transportation network and modelled transportation conditions. Thus, a subset of parameters with engineering solution is selected, or sensitivity or dispersion analysis is used to reduce the complexity of the optimization [13]. The wide range of the optimization algorithms exists, started from genetic algorithms to an enhanced simultaneous perturbation stochastic approximation (SPSA) [15]. For example, the author [16] uses the simultaneous perturbation stochastic approximation to calibrate the simulation model parameters and demand templates by using different sections. The authors advise to use an enhanced SPSA algorithm with the Bayes sampling technique. Several authors [17] use SPSA to calibrate supply and demand parameters. The driver behaviour parameters are pre-calibrated based on lane sensor data. For example, the author [18] used a simplex algorithm to perform the calibration of one parameter subset - the 
acceleration, deceleration, and lane-changing behaviour of followers. Others authors [19] model calibration based on the OptQuest/Multistart algorithm (OQMS), the author from a literature source [20] proposed hybrid calibration - calibration of microscopic models with macroscopic data. The variability of the drivers in the speed-flow ratio has to be taken into account when performing the simulation model calibration.

Authors from the literature source [21] used neural network to perform the model calibration for the roundabouts. The main unanswered questions are the optimal size of the simulation model database to train the neural network, and a way to find the acceptable neural network configuration that will provide acceptable answers. The study [23] proposed to use the Memetic algorithm (MA) for microscopic simulation model calibration.

A summary of the simulation model validation and calibration methods and parameters is given in Table 4. Data mining methods are actively used in transport management tasks, e.g., to simulate and optimize intelligent traffic signalization plans [24], to analyse the traffic accidents [25] and to preprocess the observed data to analyse the driver behaviour on the roads [26], to identify the black zones on the road [27], and to define the future transportation demand [28].

Table 4. The Summary of the simulation model validation parameters and methods

\begin{tabular}{|c|c|c|c|c|}
\hline Validation parameters & Validation methods & Calibration parameters & $\begin{array}{l}\text { Calibration } \\
\text { methods }\end{array}$ & $\begin{array}{c}\text { Simulation } \\
\text { tool }\end{array}$ \\
\hline Transportation flow intensity & $\begin{array}{l}\text { Mean square } \\
\text { percentage error, } \\
\text { GEH statistics }\end{array}$ & Global, local parameters & $\begin{array}{l}\text { Trial and error } \\
\text { method }\end{array}$ & Aimsun \\
\hline Average driving speed & Not described & $\begin{array}{l}\text { Minimum headway, speed, } \\
\text { transportation flow saturation } \\
\text { rate }\end{array}$ & Genetic algorithm & Vissim \\
\hline $\begin{array}{l}\text { Average driving time, maximum } \\
\text { queue, vehicles stops }\end{array}$ & \begin{tabular}{|l|} 
Functional indicators \\
comparison at \\
intersection inputs
\end{tabular} & $\begin{array}{l}\text { Desired speed, safety distance, } \\
\text { average headway, } \\
\text { minimal/maximal look ahead }\end{array}$ & Neural network & Vissim \\
\hline $\begin{array}{l}\text { Transportation flow intensity } \\
\text { and density }\end{array}$ & Mean absolute error & $\begin{array}{l}\text { Average drivers reaction time, } \\
\text { average arrival interval }\end{array}$ & SPSA algorithm & Paramics \\
\hline $\begin{array}{l}\text { Transportation counts such as } \\
\text { flow rate, speed, queue length } \\
\text { etc. }\end{array}$ & Mean absolute error & $\begin{array}{l}\text { Average drivers reaction time, } \\
\text { average arrival interval }\end{array}$ & Genetic algorithm & Paramics \\
\hline $\begin{array}{l}\text { Speed, transportation flow } \\
\text { intensity }\end{array}$ & Not described & $\begin{array}{l}\text { Average drivers reaction time, } \\
\text { average arrival interval }\end{array}$ & Not described & Paramics \\
\hline $\begin{array}{l}\text { Transportation flow intensity, } \\
\text { occupancy }\end{array}$ & Not described & $\begin{array}{l}\text { Average gap, average drivers } \\
\text { reaction time }\end{array}$ & Genetic algorithm & Paramics \\
\hline Transportation flow intensity & Mean absolute error & $\begin{array}{l}\text { Car-following factors, drivers' } \\
\text { aggressiveness factors }\end{array}$ & Simplex algorithm & Corsim \\
\hline Transportation flow intensity & $\begin{array}{l}\text { GEH statistics, Mean } \\
\text { error }\end{array}$ & $\begin{array}{l}\text { More than } 20 \text { parameters, e.g., } \\
\text { lane change frequency, } \\
\text { maximum turning speed, } \\
\text { pedestrian delay, headway etc. }\end{array}$ & $\begin{array}{l}\text { Memetic } \\
\text { algorithms }\end{array}$ & Corsim \\
\hline $\begin{array}{l}\text { Transportation counts such as } \\
\text { traffic flow intensity, speed, } \\
\text { queue length etc. }\end{array}$ & $\begin{array}{l}\text { Mean square error, } \\
\text { mean square } \\
\text { percentage error }\end{array}$ & Drivers behaviour parameters & Genetic algorithm & MITSIMLab \\
\hline $\begin{array}{l}\text { Transportation flow intensity } \\
\text { and speed }\end{array}$ & Not described & Drivers behaviour parameters & $\begin{array}{l}\text { Multistep } \\
\text { sensitivity analysis }\end{array}$ & MITSIMLab \\
\hline
\end{tabular}

As shown by the study of comparing genetic and clustering algorithms [29], both genetic and clustering algorithms provide practical solutions for the parameters values calibration, however, genetic algorithms require more time to find a solution.

The summary of the validation methods and parameters suggests that the authors perform model validation and calibration based on a subset of model parameters, examining the difference between the observed and simulated data over a given period of time on a typical day, or using separate transport system performance indicators or the demand templates is already pre-calibrated.

\section{Conclusion}

In the paper the general principles of the transportation simulation model development and 
validation were considered. The overview of the transportation simulation models type is given. The steps of the transportation simulation model development procedure are specified. The considered examples of simulation models are taken from the traffic organization and impact projects conducted in the Riga city.

The geometric representation of transportation network is the only the first step in the simulation model developing process. The next important step is to ensure that developed model corresponds to observe one, made the transportation simulation checking. The varied checks are presented for the transportation macroscopic and microscopic simulation model validation. There is no unified definition of the transportation simulation model validation, verification and calibration. Validation and calibration steps are used in any transportation simulation model checking process. And verification is used as the third additional check; sometimes it is included into the validation step. The summary of the parameters and methods for the transportation simulation model validation and calibration is given. The parameters and methods selection in most cases depend on the simulation tool. Transportation flow intensities are the most common used parameter for transportation simulation model validation based on the summary (Table 2). And drivers' behaviors parameters are the most used for transportation simulation model calibration. The topic for the further research is to evaluate the transport travel demand microscopic simulation model calibration procedures for transport impact analysis. The described principles of the transportation simulation model development and validation can be used to develop the acceptable and stable transportation simulation model.

\section{References:}

[1] B. R. Hellinga, Requirements for the calibration of traffic simulation models, Canadian Society for Civil Engineering, vol. IVB, 1998, pp. 211-222.

[2] T. J. Fratar, A. M. Voorhees, M. S. Raff, Forecasting distribution of interzonal vehicular trips by successive approximations/with discussion, Highway Research Board, Washington: Transportation Research board, 2008, pp. 53-65.

[3] J. Bowman, M. Ben-Akiva, Activity-based disaggregates travel demand model system with activity schedules, Transportation Research A, 2000, pp. 1-28.
[4] Transportation Impact Analyses for Site Development: An ITE Proposed Recommended Practice, translation: SIA Solvers and SIA Open World, 2007.

[5] S. Detering, L. Schnieder, E. Schniede, Twolevel validation and data acquisition for microscopic traffic simulation models, Advances in Systems and Measurements, vol. 3, 2010, pp. 48-56.

[6] J. Han, M. Kamber, J. Pei, Data Mining: Concepts and Techniques, 3rd ed., USA: Elsevier Inc., 2012, pp. 678.

[7] D. H. Lee, X. Yang, P. Chandrasekar, Parameter calibration for Paramics using genetic algorithm, Washington: TRB, 2001.

[8] Department of Transportation Federal Highway Administration, https://www.fhwa.dot.gov

[9] D. Ni, J. D. Leonard II, A. Guin, B. M. Williams, Systematic approach for validating traffic simulation models, Transportation Research Board, vol. 1876, 2004, pp. 20-32.

[10] M. Maher, Inferences on trip matrices from observations on link volumes: a Bayesian statistical approach, Transportation Research Part B: Methodological, vol. 17 (6), 1983, pp. 435-447.

[11] Nelson \ Nygaard, Adjusting Site-Level Vehicle Trip Generation Using Urbemis, San Francisko: Nelson\Nygaard Consulting Associates, 2005.

[12] G. G. Schultz, L. R. Rilett, Analysis of distribution and calibration of car-following sensitivity parameters in microscopic traffic simulation models, Transportation Research Board, vol. 1876, 2004, pp. 41-51.

[13] D.Chiopu, Applying two-step cluster qnalysis for identifying bank customers' profile, Buletinul Universit Petrol, Gaze din Ploie?ti, vol. LXII, 2010, pp. 66-75.

[14] N. Zenina, J. Merkurjevs, The Basis for the Transportation Microscopic Simulation Model Validation. 60th International Scientific Conference on Information Technology and Management Science of Riga Technical University (ITMS 2019), Proceedings, Latvia, Riga, 10-11 October, 2019.

[15] M. Ben-Akiva, L. Lu, Y. Xu, A. Constantinos, An enhanced SPSA algorithm for the calibration of dynamic traffic assignment models, Transportation Research Part C, vol. 51, 2015, pp. 149-166.

[16] I. I. Otkovi, T. Tollazzi, M. Raml, Calibration of microsimulation traffic model using neural network, Expert Systems with Applications, vol. 40, 2013, pp. 5965-5974. 
[17] R. Balakrishna, C. Antoniou, M. Ben-Akiva, H. N. Koutsopoulos, Y. Wen, Calibration of microscopic traffic simulation models: method and application, Transportation Research Board, vol. 1999, 2007, 198-207.

[18] A. Khalik, M. A.-T. Amal, Prediction analysis of trip production using cross-classification technique, Al-Rafidain Engineering, vol. 14 (4), 2006, pp. 51-63.

[19] A. Chen, P. Chootinan, W. W. Recker, Examining the quality of synthetic origindestination trip table estimated by path flow estimator, Transportation engineering, 2005, pp. 506-513.

[20] UK Highways, Design Manual for Roads and Bridges, UK Highways Agency, 1992.

[21] J. D. Ortuzar, L. G. Willumsen, Modelling transport, 4th ed., John Wiley \& Sons 1td., 2011 , p. 586.

[22] N. Zenina, A. Romanovs, J. Merkuryev, TRIP-based transport travel demand model for intelligent transport system measure evaluation based on micro simulation. International Journal of Simulation and Process Modelling, 2017, Volume 12, Issue 3-4, pp.207-220.

[23] D. Pavlyuk, V. Gromule, Discrete choice model for a prefered transportation mode, Proc. of the 10th International Conference Reliability and statistics in transportation and communication, Riga: Transport and Telecommunication Institute, 2010, pp. 143152.

[24] J. G. Wardrop, Some theoretical aspects of road traffic research, Institute of Civil Engineers, vol. 1 (3), 1952, pp. 352-362.

[25] V. C. Tatineni, M. J. Demetsky, Supply Chain Models for Freight Transportation Planning, University of Virginia, 2005.

[26] G. List, L Konieczny., C. Durnford, A best practice truck flow estimation model for the new, Transportation Research Record, Washington: Transportation research board, 2002, pp. 97-103.

[27] J. Rzeszotko, S. H. Nguyen, Machine learning for traffic prediction, Pu?tusk: International Workshop on Concurrency, Specification and Programming, 2011, pp. 442-453.

[28] E., Ruiter M. Ben-Akiva, Disaggregate travel demand models for the San Francisco bay area, Transportation Research Record, 1978, pp. 121-128.

[29] K. Daehyon, Neural networks for trip generation model, Eastern Asia Society for Transportation studies, Vol. 2 (4), 2001, pp. 201-207.
[30] International provider of software and services for traffic planning, simulation and prediction, https://www.aimsun.com

[31] Aimsun next modelling guidelines, Nevada department of Transportation, June 2018.

[32] SMART Goals: A How to Guide, University of California, 2017.

[33] Методические рекомендации по разработки и реализации мероприятий по организации дорожного движения (in russian), Moscow, 2017.

[34] UK Highways, Design Manual for Roads and Bridges, UK Highways Agency. 1992.

[35] J. Schlaich, U. Heidl, P.Mohl, Multimodal macroscopic transport modelling: State of the Art with a focus on validation \& approval, 17th IRF World Meeting \& Exhibition, 2013.

[36] E.Daniševska birojs and Solvers Thinking Ahead, Rīgas domes autonovietnu politikas un attīstības koncepcijas izstrāde Stāvparku sistēmas sadaḷas attīstības plans (In Latvian), 2013.

[37] E.Daniševska birojs and Solvers Thinking Ahead, Transporta plūsmu izpētes un prognozes projekts ēku kompleksam teritorijai starp Rūpniecības, Pētersalas un Katrīnas ielām (In Latvian), 2008.

[38] E.Daniševska birojs and Solvers Thinking Ahead, Satiksmes plūsmu detalizēta izpēte Liepājas pilsētas centra teritorijai starp Krišjāṇa Valdemāra ielu, Jūrmalas ielu, Siena ielu, Kuršu laukumu, Malkas ielu, Kungu ielu, Bāriņu ielu, Kārḷa Zāles laukumu un Jūras ielu. (In Latvian), 2009.

[39] E.Daniševska birojs and Solvers Thinking Ahead, Satiksmes plūsmu izpētes un modelēšanas projekts Brīvības gatvei no Gustava Zemgales gatves līdz Krustabaznīcas ielai (In Latvian), 2011.

[40] H. Largo, P. J. G. Ribeiro, G. Dias, C. P. B. Trujillo, Public Transportation Demand Model for Low Density Territories, WSEAS Transactions on Environment and Development, 2019, vol. 15, pp. 395-407.

[41] A. Carteni, A Cost-Benefit Analysis Based on the Carbon Footprint Derived from plug-in Hybrid Electric Buses for Urban Public Transport Services, WSEAS Transactions on Environment and Development, vol. 14, 2018, pp. 125-135.

[42] M. Botte, B. Montella, L. Dacierno, A Geometrical Approach to Reduce Calculation Times in the Definition of Rail Convoy Speed Profiles, WSEAS Transactions on Environment and Development, vol. 16, 2020, pp. 98-104. 